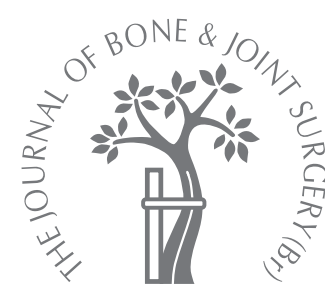

\title{
A comparison of survival of moulded monoblock and modular tibial components of 751 AGC total knee replacements in the treatment of rheumatoid arthritis
}

\author{
A.-K. Himanen, \\ E. A. Belt, \\ M. U. K. Lehto, \\ M. M. J. \\ Hämäläinen
}

From Rheumatism Foundation Hospital, Heinola, Finland

\begin{abstract}
We evaluated the survival of moulded monoblock and modular tibial components of the AGC total knee replacement in patients with rheumatoid arthritis. Between 1985 and 1995, 751 knees with this diagnosis were replaced at our institution. A total of 256 tibial components were of the moulded design and 495 of the modular design. The mean followup of the moulded subgroup was 9.6 years $(0.5$ to 14.7$)$, and that of the modular group 7.0 years (0.1 to 14.7).

The groups differed significantly from each other in Larsen grade, cementing of components and patellar resurfacing, but no statistically significant difference between the survival of the components was found (Log rank test, $p=0.91$ ). The cumulative success rate of the moulded group was $96.8 \%$ (95\% confidence interval $93.6 \%$ to $98.4 \%$ ) at five years and $\mathbf{9 4 . 4} \%$ (95\% confidence interval $90.4 \%$ to $96.7 \%$ ) at ten years, and of the modular group 96.2\% (95\% confidence interval $94 \%$ to $97.6 \%$ ) and $93.6 \%(95 \%$ confidence interval $89.7 \%$ to $96 \%)$, respectively. Revision was required in 37 total knee replacements, the main causes were infection, pain, loosening of the tibial component and patellar problems. Survival rates for both components were satisfactory.
\end{abstract}

Total knee replacement (TKR) usually provides good results in patients with rheumatoid arthritis, but can be technically difficult owing to the poor quality of the bone and the surrounding soft tissues. ${ }^{1-3}$ High levels of satisfaction for relief of pain and range of movement with low rates of revision have been reported. ${ }^{4-7}$ A significantly lower risk of failure in TKR has been associated with rheumatoid arthritis as the underlying diagnosis. ${ }^{8}$ However, some studies have reported worse outcomes in rheumatoid arthritis than in osteoarthritis. 9,10 $^{-10}$

Flat-on-flat total condylar knee prostheses were developed in order to achieve a low rotational constraint and to preserve posterior femoral rollback and normal knee joint function. ${ }^{11}$ In the evaluation of 34000 TKRs, the AGC knee (Anatomically Graduated Components, Biomet Inc., Warsaw, Indiana) had a lower revision rate than any other design. ${ }^{12}$ The prevention of tibial loosening and polyethylene wear have been challenging in the development of the tibial component of flaton-flat designs. Problems have been encountered with thin polyethylene with a flat surface, resulting in line contact rather than area contact, which produces high contact stresses and accelerated rates of wear. ${ }^{11,13-15}$
Modular tibial components have been widely adopted, offering the intra-operative option of changing the thickness of the polyethylene components. Additionally, at revision the possibility of an isolated tibial insert exchange while retaining well-fixed components is available. ${ }^{16}$ However, disadvantages of modularity include breakage of modular couplings, fretting and corrosion of the modular baseplate, and backside wear of the polyethylene insert. ${ }^{17}$

The purpose of this study was to evaluate differences in the survival of moulded and modular AGC tibial components in patients with rheumatoid arthritis at mid-term follow-up.

\section{Patients and Methods}

Between September 1985 and December 1995 a total of 586 patients (106 males, 480 females) with rheumatoid arthritis underwent TKR using the AGC prosthesis. Of these, 165 patients had bilateral replacements during the study, producing a total of 751 replacements. The surgery involved 12 surgeons at our institution (Rheumatism Foundation Hospital). The TKRs were performed using non-constrained, posterior cruciate-retaining flat-onflat components. Two versions of tibial component were used: the moulded tibial component, 
Table I. Demographics and clinical data of the 586 patients who had AGC total knee replacement

\begin{tabular}{|c|c|c|c|}
\hline Variables & $\begin{array}{l}\text { Group A } \\
\text { (Moulded } n=256 \text { ) }\end{array}$ & $\begin{array}{l}\text { Group B } \\
\text { (Modular } n=495 \text { ) }\end{array}$ & p-value \\
\hline \multicolumn{4}{|l|}{ Demographics } \\
\hline Number of females (\%) & $215(84)$ & $406(82)$ & 0.50 \\
\hline Mean age in yrs (range) & $58(23$ to 80$)$ & 60 (24 to 84$)$ & 0.098 \\
\hline Mean weight in kg (range) & 66 (36 to 101$)$ & 68 (37 to 125$)$ & 0.018 \\
\hline \multicolumn{4}{|l|}{ Clinical } \\
\hline Number of Larsen grade 5 & )$^{*} 186(74)$ & $288(62)$ & $<0.001$ \\
\hline Number cemented (\%) & $142(55)$ & $318(64)$ & 0.019 \\
\hline Patella resurfaced $(\%)$ & & & $<0.001$ \\
\hline None & $81(32)$ & $360(73)$ & \\
\hline Metal-backed & $170(66)$ & $81(16)$ & \\
\hline All-polyethylene & $5(2)$ & $54(11)$ & \\
\hline
\end{tabular}

"there were 32 anteroposterior radiographs missing from the study group, so there were only 253 in group $A$ and 466 in group $B$

in which compression-moulded ultra-high-molecular weight polyethylene (UHMWPE) was attached directly to a cobalt chrome metal tray with a central stem by the manufacturer; and the modular design, in which there was a baseplate of titanium into which the surgeon inserted a modular power-milled polyethylene component at operation. The moulded model was the original AGC design, and the modular model was introduced in 1989. A total of 256 tibial components were of the moulded design (group A) and 495 of the modular design (group B). The patients were allocated depending on the year of the operation and the component available to the surgeon at that time. The differences between groups in component fixation (cemented/ cementless) were also analysed (Table I). If cement was used, all components were cemented; there were no hybrids. Whether cement was used was dependent on the operating protocol at the time of operation and whether intra-operative circumstances required it.

Clinical and radiological data were collected from the patient documents, radiographs and European League against Rheumatism (EULAR) charts ${ }^{18}$ by the surgeons. Deaths and causes for revision surgery were gathered from the National Arthroplasty Register. Pre-operative details, including the patient's age, gender, weight and the Larsen, Dale and $\mathrm{Eek}^{19}$ grade of the arthritic change ranging from 0 to 5 points, in which 0 is a normal knee and 5 represents severe destruction are also shown in Table I.

The two groups differed significantly with regard to the number of knees assessed as Larsen grade 5, the numbers of cemented components and patellae resurfaced, and also the mean weight. There were 186 Larsen grade 5 knees in group A, and 288 in group B. Cementing was the most common form of fixation. A total of 142 TKRs (55\%) were cemented in group A and 318 (64\%) in group B. The femoral component was made of cobalt-chromium, and the design was universal with no specific geometry for the right or left side. The contact between the femoral and tibial component was of a non-constrained line-type. The patella was resurfaced in 310 cases, of which 59 were all-polyethy- lene components ( 5 in group A, 54 in group B) and 251 were of a metal-backed design (170 in group A and 81 in group B). In group A 175 (68\%) of the patellae were resurfaced. In group B the patella was resurfaced only in 135 $(27 \%)$ of the knees. The mean weight of the patients was $66 \mathrm{~kg}$ (36 to 101) in group A, and $68 \mathrm{~kg}$ (37 to 125) in group $\mathrm{B}$, and the mean age of the patients in group $\mathrm{A}$ was 58 years (23 to 80 ), and in group B 60 years (24 to 84 ) (Table I).

The incidence of radiolucent lines at the bone-cement or bone-implant interfaces was determined by examination of orthogonal anteroposterior and lateral radiographs. The results were recorded as millimetres by the zone of the tibial component $^{20}$ (Fig. 1) by a researcher (A-KH). Radiolucent lines were defined as any parallel-sided gap greater than 1 $\mathrm{mm}$ in width at the interface. The position of the tibial component was measured on plain radiographs relative to the long axis of the tibia in both sagittal and coronal planes, by analysing the anteroposterior slope of the tibial component from a lateral projection, and the tilt of the component from an AP projection. The accuracy of the measurements was within $1^{\circ}$. Clinical outcome was estimated according to the EULAR post-operative assessment chart, which assesses general locomotor status, detailed symptoms, functional ability and the findings of the physical examination. ${ }^{21}$ Ability to climb stairs with a reciprocating gait without using a hand rail, to walk more than $1 \mathrm{~km}$ without interruption and the absence of pain were regarded as signs of clinical success. Clinical and radiological parameters were followed up for four years post-operatively.

Kaplan-Meier ${ }^{22}$ survival analysis was applied to the tibial component. Death of the patient, the end of the year 2000 , or revision surgery with removal, exchange or addition of any prosthetic component, served as end-points. The mean follow-up was 7.9 years (0.1 to 14.7$)$. For group A alone the mean follow-up was 9.6 years $(0.5$ to 14.7$)$ and for group B, follow-up was 7 years ( 0.1 to 14.7$)$. At the start of our study only the moulded tibial component was implanted, and from 1989 both moulded and modular 


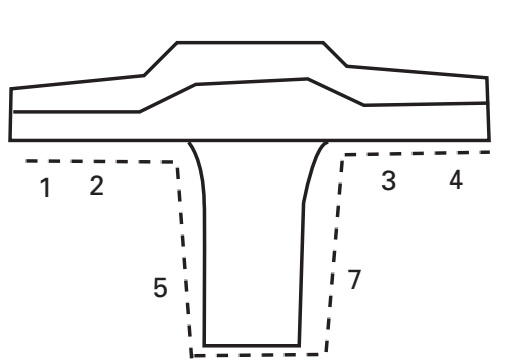

medial lateral

Fig. 1

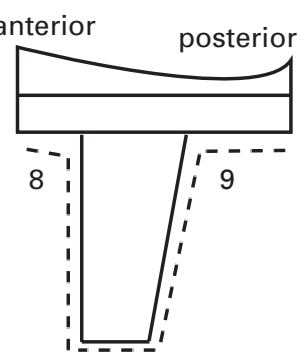

10

Tibial zones in radiological analysis of radiolucent lines.

Table II. Proportional hazard model to determine the effect of variables on the risk of revision of the AGC prostheses in rheumatoid arthritis

\begin{tabular}{|c|c|c|}
\hline Variable & Hazard ratio* $\left(95 \% \mathrm{Cl}^{\dagger}\right)$ & p-value \\
\hline Female gender & $0.62(0.29$ to 1.42$)$ & 0.27 \\
\hline Age (per year) & $0.98(0.95$ to 1.01$)$ & 0.24 \\
\hline Weight (per kg) & 1.01 (0.99 to 1.03$)$ & 0.45 \\
\hline Larsen grade 5 & $1.30(0.59$ to 2.86$)$ & 0.64 \\
\hline Cemented & $1.52(0.56$ to 4.14$)$ & 0.41 \\
\hline \multicolumn{3}{|l|}{ Patella resurfaced } \\
\hline None & Reference $^{\ddagger}$ & \\
\hline Metal-backed & $1.52(0.70$ to 3.31$)$ & 0.29 \\
\hline All-polyethylene & $1.95(0.60$ to 6.33$)$ & 0.27 \\
\hline Modular type of tibia component & $1.15(0.51$ to 2.57$)$ & 0.74 \\
\hline Tibial tilt & $1.10(0.47$ to 2.58$)$ & 0.83 \\
\hline \multicolumn{3}{|l|}{ Tibial slope } \\
\hline Neutral & Reference $^{\ddagger}$ & \\
\hline Anterior & $3.06(0.68$ to 13.71$)$ & 0.14 \\
\hline Posterior & $1.93(0.44$ to 8.46$)$ & 0.38 \\
\hline
\end{tabular}

models were used. At the beginning of the 1990's the modular design was favoured, especially in younger patients, but no formal process of randomisation was applied for this study.

Statistical analysis. The results were expressed as the mean, range, and $95 \%$ confidence intervals (CI). Statistical comparison between the groups was performed using the $t$-test or the chi-squared test. A p-value $<0.05$ was considered statistically significant. The prognostic factors predicting the duration of the revision-free survival time were analysed using Cox's multivariate proportional hazard regression models. Cumulative success rate was constructed using the Kaplan-Meier ${ }^{22}$ method, and differences between the groups was tested by using the permutation type log-rank

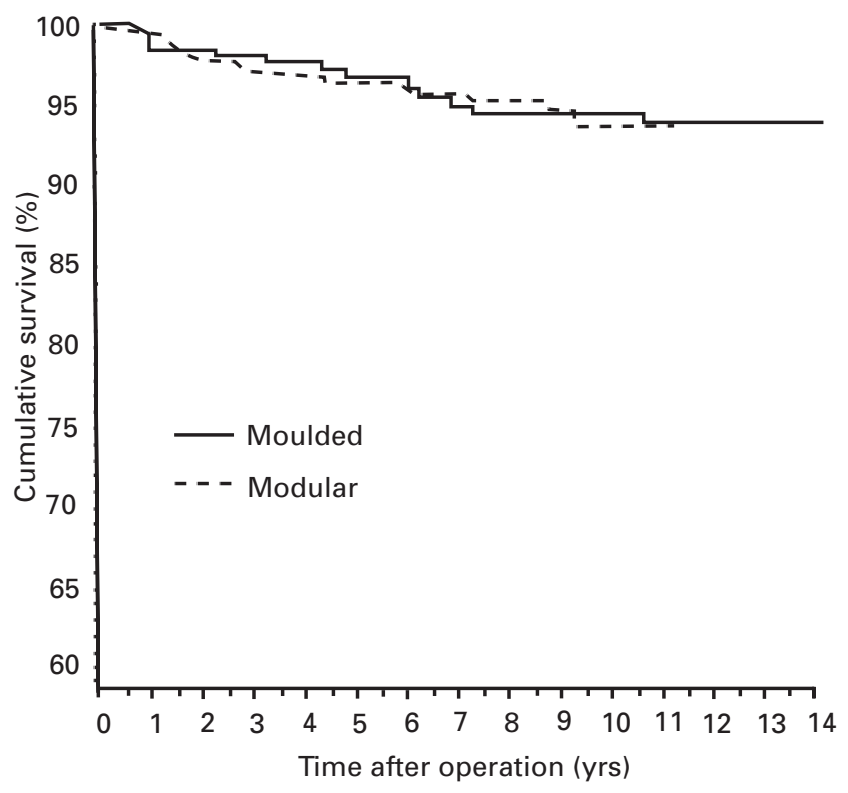

Fig. 2

Cumulative survival of moulded and modular subgroups of the AGC knees (please see text for information on confidence intervals).

Table III. Percentages of radiolucent lines in the tibial zones of the moulded and modular tibial designs of AGC knee prosthesis

\begin{tabular}{|c|c|c|c|}
\hline \multirow[b]{2}{*}{ Zone } & \multicolumn{2}{|c|}{ Four years cumulative translucencies } & \multirow[b]{2}{*}{ p-value } \\
\hline & $\begin{array}{l}\text { Group A (moulded) } \\
\left(95 \% \mathrm{Cl}^{*}\right)\end{array}$ & $\begin{array}{l}\text { Group B (modular) } \\
(95 \% \mathrm{Cl})\end{array}$ & \\
\hline 1 & 17 (11 to 26$)$ & $17(12$ to 24$)$ & 0.98 \\
\hline 2 & 11 (7 to 20$)$ & $7(4$ to 13$)$ & 0.27 \\
\hline 3 & 7 (4 to 15$)$ & 7 (4 to 13$)$ & 0.90 \\
\hline 4 & 13 (8 to 22 ) & 12 (8 to 19$)$ & 0.92 \\
\hline 5 & 6 (2 to 13$)$ & $4(2$ to 8$)$ & 0.75 \\
\hline 6 & $1(0$ to 8$)$ & $3(1$ to 8$)$ & 0.40 \\
\hline 7 & 6 (3 to 14$)$ & $3(1$ to 8$)$ & 0.24 \\
\hline 8 & 36 (28 to 46$)$ & 20 (15 to 27$)$ & 0.002 \\
\hline 9 & 26 (19 to 36$)$ & $14(10$ to 21$)$ & 0.011 \\
\hline 10 & $4(2$ to 10$)$ & $5(2$ to 10$)$ & 0.96 \\
\hline
\end{tabular}

test. Success was defined as a prosthesis still in situ at the end of the follow-up, regardless of clinical score or radiological findings.

\section{Results}

The Cox's proportional hazard regression analysis assessing the effect of variables on the risk of revision of the AGC prostheses found that the demographic variables of gender, age and weight, and clinical variables, including Larsen grading, use of cement, resurfacing of the patella, type of tibial component or its post-operative positioning, had no statistically significant influence on the risk of revision (Table II). 
Table IV. Clinical results at the four year post-operative followup of AGC total knee replacements

\begin{tabular}{|c|c|c|c|}
\hline & \multicolumn{2}{|c|}{ Tibial component } & \multirow[b]{2}{*}{ p-value ${ }^{*}$} \\
\hline & $\begin{array}{l}\text { Group A } \\
\text { (moulded) }\end{array}$ & $\begin{array}{l}\text { Group B } \\
\text { (modular) }\end{array}$ & \\
\hline \multicolumn{4}{|l|}{ Pain (\%) } \\
\hline No & 78 & 75 & 0.61 \\
\hline Yes & 22 & 25 & \\
\hline \multicolumn{4}{|l|}{ Walking ability (\%) } \\
\hline$>1 \mathrm{~km}$ & 50 & 40 & 0.15 \\
\hline$<1 \mathrm{~km}$ & 50 & 60 & \\
\hline \multicolumn{4}{|l|}{ Ascending etc (\%) } \\
\hline Reciprocating gait & 21 & 29 & 0.24 \\
\hline Non-reciprocating gait & 79 & 71 & \\
\hline
\end{tabular}

Table V. Causes for revision surgery of the AGC in rheumatoid arthritis

\begin{tabular}{lll}
\hline & $\begin{array}{l}\text { Group A } \\
\text { (Moulded } \mathbf{n ~ = ~ 1 4 ) ~}\end{array}$ & $\begin{array}{l}\text { Group B } \\
\text { (Modular n = 23) }\end{array}$ \\
\hline Pain & 2 & 5 \\
Poor range of movement & 0 & 1 \\
Instability & 2 & 0 \\
Migration of component & & \\
$\quad$ Tibial & 2 & 5 \\
$\quad$ Femoral & 1 & 0 \\
$\quad$ Patellar & 0 & 1 \\
$\quad$ & 1 & 2 \\
Fracture of patellar component & & \\
Fracture & 1 & 2 \\
$\quad$ Femur or tibia & 0 & 1 \\
$\quad$ Patella & & 5 \\
Infection & 5 & 1 \\
$\quad$ Audible patellar crepitus & 0 & \\
\hline
\end{tabular}

* $95 \% \mathrm{Cl}, 95 \%$ confidence interval

There was no statistically significant difference between the cumulative success rates in the two groups (Log rank, $\mathrm{p}=0.91$ ). The cumulative success rate in group $\mathrm{A}$ at five years was $96.8 \%$ (95\% CI $93.6 \%$ to $98.4 \%$ ) and $94.4 \%$ at ten years (95\% CI $90.4 \%$ to $96.7 \%)$. In group B the survival rate was $96.2 \%(95 \%$ CI $94.0 \%$ to $97.6 \%$ ) at five years and $93.6 \%$ (95\% CI $89.7 \%$ to $96.0 \%$ ) at ten years (Fig. 2).

Cumulative success rates for the femoral component at five years and ten years in group A were 98.0\% $195 \% \mathrm{CI}$ $95.2 \%$ to $99.1 \%$ ) and $96.6 \%$ (95\% CI $93.2 \%$ to $98.3 \%$ ), respectively. The cumulative success rates for the femoral component at five and ten years in group B were $98.7 \%$ (95\% CI $97.2 \%$ to $99.4 \%$ ) and 97.7 (95\% CI $94.8 \%$ to $99.0 \%$ ), respectively. The cumulative success rates for the tibial component in group A were 98.0\% (95\% CI 95.1\% to $99.1 \%$ ) at five years and $95.6 \%$ (95\% CI $91.9 \%$ to $97.6 \%)$ at ten years and in group B were $97.5 \%$ (95\% CI
$95.6 \%$ to $98.6 \%$ ) and $96.4 \%$ (95\% CI $93.5 \%$ to $98.0 \%$ ), respectively.

On radiological follow-up there was no statistically significant difference between the groups with respect to the radiolucent lines in the zones estimated from the anteroposterior radiographs (zones 1 to 7 ). Surprisingly, there were more radiolucent lines in the moulded group when sagittal zones indicating anterior and posterior translucencies were examined (chi-squared test, zone 8, p = 0.002; zone 9, $\mathrm{p}=0.011$ ) (Fig. 1, Table III). The clinical outcome did not differ significantly between the groups, judged by the subjective assessment of the severity of pain, the uninterrupted walking ability and the ability to ascend and descend stairs at the four-year post-operative evaluation (Table IV).

At the end of the survey, 37 knees had undergone revision; for infection in ten, pain in seven and loosening of the tibial component in seven. Revision was undertaken in six knees because of patellar problems: a fracture of the patella had occurred in one knee, and a fracture of the patellar component in three, audible crepitus was heard from the patella in one knee, and migration of the patellar component occurred in one case. Migration of the femoral component occurred in one case. Instability caused revision in two cases, and fracture of the femur in two and of both the tibia and femur in one, and one knee with a poor range of movement accounted for the remaining revision. Pain was mostly located anteriorly, suggesting a patellar origin. Accordingly, in six knees the patella was resurfaced at revision (Table V). Subsidence or change in the position of the tibial component indicating aseptic loosening was slightly more common in the modular group (two in group A and five in group B).

\section{Discussion}

This study is one of the largest series of TKRs in patients with rheumatoid arthritis. The AGC prosthesis has given good results in difficult cases of juvenile chronic arthritis ${ }^{23}$ as well as in treating patients with osteoarthritis or rheumatoid arthritis. ${ }^{24}$ In the latter condition TKRs tend to survive longer than in osteoarthritic patients, ${ }^{8}$ possibly because of the reduced activity levels. A study examining outcome of patients with rheumatoid arthritis treated with a posterior cruciate ligament (PCL)-retaining prosthesis identified a high rate of posterior instability and recurvatum deformity, resulting in revision at which the PCL was found to be absent and synovial reaction was present. A posterior stabilised prosthesis was thought to be the preferred choice in these circumstances. ${ }^{25}$ However, in our patients this was not a major cause of revision.

We found no significant difference between the survival of moulded and modular tibial components. In most other studies a slight superiority of the moulded design has been noted. In a series of 4583 AGC TKRs, a survival rate of $98.86 \%$ at 15 years was found with 36 knees at risk. The advantage of the moulded design in eliminating back-sided 
wear of the polyethylene component was emphasised. ${ }^{26} \mathrm{~A}$ $90 \%$ survival at ten years for modular metal-backed tibial components and $92 \%$ survival for the non-modular design has been reported in another study. ${ }^{27}$ In a series of 1071 primary AGC TKRs, better clinical and radiological results were achieved with a compression-moulded monoblock than with a modular design. ${ }^{28}$ A study involving 3152 AGC prostheses with moulded tibial components identified 41 tibial failures $(1.3 \%) .{ }^{29}$ The main mechanisms of failure for moulded tibial components with cemented fixation was collapse of the medial tibial plateau, ligamentous imbalance, progressive radiolucencies and pain. ${ }^{29}$

The difference between the groups in the incidence of radiolucencies noticed in anterior and posterior zones raised questions about the significance of the I-beamshaped tibial stem in the moulded tibia and the fluted stem in the modular design. Peters et al, ${ }^{30}$ in their biomechanical study on cadavers mentioned no differences in tibial component motion between I-beam and cruciate-shaped stemmed components fixed with the surface-cemented technique in a limited loading protocol, which did not include testing with torsion or shear. The clinical relevance of the radiolucencies noticed can also be debated. Smith, Naima and Freeman ${ }^{31}$ found early-onset radiolucent lines beneath the tibial cement to be related to the presence of pre-operative sclerosis, and to be non-progressive and having no effect on fixation. In our study, neither the different tibial stem designs nor the differences between cemented zones were analysed.

In this study revision surgery was the end-point, not the radiological changes. The polyethylene wear was not analysed, but backside wear and cold flow are concerns in modular tibial designs. ${ }^{32}$ Micromotion causing fretting at the modular interface has been reported, and improvements in locking mechanisms have been recommended. ${ }^{32}$ In an analysis of different modular inserts, wear of the non-articulating surface of the tibial insert occurred frequently, independently of the capture mechanism. ${ }^{33}$ From this point of view, the moulded component, in which UHMWPE has been compression moulded directly to the baseplate, might offer advantages in avoiding the production of polyethylene debris and osteolysis. ${ }^{26,34-36}$

The mid-term mean follow-up of 7.9 years may be too soon for backside wear of the modular design to be apparent. Additionally, the follow-up of the modular group was shorter than that of the moulded group.

There was a statistically significant difference in the number of knees graded as Larsen 5 between the moulded and modular groups. Despite the severity of the rheumatoid process, surprisingly few revisions were due to problems with the patella, even with the old-fashioned, metal-backed design, which was mainly in use at the beginning of the study.

Our mid-term follow-up results using the AGC prosthesis in TKRs in patients with rheumatoid arthritis are satisfactory using either the moulded or the modular tibial component. Neither fixation of the tibial and femoral components (cemented/cementless), resurfacing of the patella, or the type of patellar component had an impact on survvial. It may be that a longer follow-up will be required to reveal any difference in outcome for the two types of tibial component.

No benefits in any form have been received or will be received from a commercial party related directly or indirectly to the subject of this article.

\section{Supplementary Material}

$\dddot{\mathrm{e}}$ A further opinion by Dr K Trieb is available with the electronic version of this article on our website at www.jbjs.org.uk

\section{References}

1. Chmell MJ, Scott RD. Total knee arthroplasty in patients with rheumatoid arthritis. Clin Orthop 1999;366:54-60.

2. Ebert FR, Krackow KA, Lennox DW, Hungerford DS. Minimum 4-year follow-up of the PCA total knee arthroplasty in rheumatoid patients. J Arthroplasty 1992;7:1018.

3. Yang J-P., Bogoch ER, Woodside TD, Hearn TC. Stiffness of trabecular bone of the tibial plateau in patients with rheumatoid arthritis of the knee. J Arthroplasty 1997:12:798-803

4. Robertsson O, Knutson K, Lewold S, Goodman S, Lidgren L. Knee arthroplasty in rheumatoid arthritis: a report from the Swedish Knee Arthroplasty Register on 4,381 primary operations 1985-1995. Acta Orthop Scand 1997;68:545-53.

5. Rodriguez JA, Saddler S, Edelman S, Ranawat CS. Long-term results of total knee arthroplasty in class 3 and 4 rheumatoid arthritis. J Arthroplasty 1996;11:141-5.

6. Schai PA, Scott RD, Thornhill TS. Total knee arthroplasty with posterior cruciate retention in patients with rheumatoid arthritis. Clin Orthop 1999;367:96-106.

7. Sledge CB, Walker PS. Total knee arthroplasty in rheumatoid arthritis. Clin Orthop 1984;182:127-36

8. Rand JA, Ilstrup DM. Survivorship of total knee arthroplasty. J Bone Joint Surg [Am] 1991;73-A:397-409.

9. Nafei A, Kristensen 0, Knudsen HM, Hvid I, Jensen J. Survivorship analysis of cemented total condylar knee arthroplasty: a long-term follow-up report on 348 cases. J Arthroplasty 1996;11:7-10.

10. Kristensen $\mathbf{0}$, Kjaersgaard-Andersen P, Hvid I, Jensen J. Long-term results in patients who have rheumatoid arthritis. J Bone Joint Surg [Br] 1992;74-B:803-6.

11. StiehI JB, Komistek RD, Dennis DA. Detrimental kinematics of a flat on solat total condylar knee arthroplasty. Clin Orthop 1999;365:139-48.

12. Knutson K, Lewold S, Robertsson 0, Lidgren L. The Swedish knee arthroplasty register: a nationwide study of 30,003 knees 1976-1992. Acta Orthop Scand 1994:65:375-86.

13. Feng EL, Stulberg SD, Wixson RL. Progressive subluxation and polyethylene wear in total knee replacements with flat articular surfaces. Clin Orthop 1994;299:60-71.

14. Bartel DL, Bicknell VL, Wright TM. The effect of conformity, thickness, and material on stresses in ultra-high molecular components for total joint replacement. $J$ Bone Joint Surg [Am] 1986;68-A:1041-51.

15. Blunn GW, Walker PS, Joshi A, Hardinge K. The dominance of cyclic sliding in producing wear in total knee replacements. Clin Orthop 1991;273:253-60.

16. Engh CA, Koralewicz LM, Pereles TR. Clinical results of modular polyethylene insert exchange with retention of total knee arthroplasty components. J Bone Joint Surg $[A m] 2000 ; 82-A: 516-23$.

17. Rand JA. Modularity in total knee arthroplasty. Acta Orthop Belg 1996;62(Suppl 1):180-6.

18. No authors listed. European League Against Rheumatism. www.eular.org (date last accessed 26th March 2007).

19. Larsen A, Dale K, Eek M. Radiographic evaluation of rheumatoid arthritis and related conditions by standard reference films. Acta Radiol Diagn (Stockh) 1977;18:481-91.

20. Ewald FC.The Knee Society total knee arthroplasty roentgenographic evaluation and scoring system.Clin Orthop 1989;248:9-12.

21. Hämäläinen $\mathbf{M}$. Knee replacement arthroplasty in patients with rheumatoid arthritis. PhD thesis, University of Kuopio, 1985: original reports 4/1985.

22. Kaplan EL, Meier P. Nonparametric estimation from incomplete observations. J Am Stat Assn 1958; $53: 457-81$ 
23. Lybäck CO, Belt EA, Hämäläinen MMJ, et al. Survivorship of AGC knee replacements in juvenile chronic arthritis: 13 year follow-up of 177 knees. Arthroplasty 2000;15:166-70

24. Himanen A-K, Belt $E$, Nevainen J, Hämäläinen $M$, Lehto MU. Survival of the AGC total knee arthroplasty is similar for arthrosis and rheumatoid arthritis: Finnish Arthroplasty Register report on 8,467 operations carried out between 1985 and 1999. Acta Orthop 2005;76:85-8.

25. Laskin RS, O'Flynn HM. Total knee replacement with posterior cruciate ligament retention in rheumatoid arthritis: problems and complications. Clin Orthop 1997;345:24-8.

26. Ritter MA, Berend ME, Meding JB, et al. Long-term followup of anatomic graduated components posterior cruciate-retaining total knee replacement. Clin Orthop 2001;388:51-7.

27. Rand JA, Trousdale RT, Ilstrup DM, Harmsen WS. Factors affecting the durability of primary total knee prostheses. J Bone Joint Surg [Am] 2003;85-A:259-65.

28. Weber AB, Worland RL, Keenan J, Van Bowen J. A study of polyethylene and modularity issues in $>1000$ posterior cruciate-retaining knees at 5 to 11 years. $J$ Arthroplasty 2002;17:987-91.
29. Berend ME, Ritter MA, Meding JB, et al. Tibial component failure mechanisms in total knee arthroplasty. Clin Orthop 2004;428:26-34.

30. Peters CL, Craig MA, Mohr RA, Bachus KN. Tibial component fixation with cement. Clin Orthop 2003:409:158-68.

31. Smith S, Naima VSN, Freeman MAR. The natural history of tibial radiolucent lines in a proximally cemented stemmed total knee arthroplasty. J Arthroplasty 1999;14:3-

32. Parks NL, Engh GA, Topolenski LDT, Emperado J. Modular tibia insert micromotion: a concern with contemporary knee implants. Clin Orthop 1998;356:10-15.

33. Conditt MA, Stein JA, Noble PC. Factors affecting severity of backside wear of modular tibial inserts. J Bone Joint Surg [Am] 2004;86-A:305-11.

34. Ritter MA, Worland R, Salinski J, et al. Flat-on-flat, nonconstrained, compression molded polyethylene total knee replacement. Clin Orthop 1995;321:79-85.

35. Ritter MA. Direct compression molded polyethylene for total hip and knee replacements. Clin Orthop 2001;393:94-100.

36. Thadani P, Vince KG, Ortaaslan SG, Blackburn DC, Cudiamat CV. Ten to 12-year followup of the Insall-Burstein I total knee prosthesis. Clin Orthop 2000;380:17-29. 